\title{
Health Monitoring and Evaluation in Remote Areas: The Case of the HPP Jirau in the Amazon, Brazil
}

\author{
Viviane de Oliveira Béghin, Assed Naked Haddad \\ Polytechnic School, Federal University of Rio de Janeiro, Rio de Janeiro, Brazil \\ Email address: \\ vivianebeghin@gmail.com(V.de O.Béghin), assed@poli.ufrj.br(A. N. Haddad)
}

To cite this article:

Viviane de Oliveira Béghin, Assed Naked Haddad. Health Monitoring and Evaluation in Remote Areas: The Case of the HPP Jirau in the Amazon, Brazil. Journal of Health and Environmental Research. Vol. 4, No. 2, 2018, pp. 69-76. doi: 10.11648/j.jher.20180402.14

Received: May 4, 2018; Accepted: May 22, 2018; Published: June 12, 2018

\begin{abstract}
This study aims to provide an overview of the health care system in specific regions of the Amazon, before and after the construction of Jirau Hydro Power Plant (HPP) to evaluate the efficiency of health activities planned and executed in the scope of the environmental licensing of the project. We studied the health conditions before the implantation of the project, identified the main characters and criteria involved on the definition of health issues and obligations assigned to the entrepreneur, as well as the results on heath inherent of those obligations, evaluated through qualitative and quantitative indicators, applied in different time cuts. The data used to define the quantitative indicators was obtained from the Municipal Health Department of the Municipality of Porto Velho and from heath units located in the studied region. As for the qualitative indicators, the data was obtained from structured questionnaires applied to part of the local population, users of the public health system.
\end{abstract}

Keywords: Qualitative and Quantitative Indicators, Monitoring and Evaluation in Health, Primary Health Care, Hydro Power Plants, Amazon

\section{Introduction}

Reality has shown that the greatest health risks resulting from environmental changes are faced by marginalized populations, poor communities and indigenous people, especially vulnerable to risks of diseases, with few resources and active voice in decision that can impact health [1-3]. The health problems that most affect these groups are infectious diseases and malnutrition $[1,4]$.

Despite numerous and clear provisions regarding human health in Brazilian infra-constitutional environmental legislation, especially Law n. 6.938 / 81 [5], which provides for the National Environmental Policy and CONAMA Resolution n. 001/86 [6], which governs the basic criteria and general guidelines for environmental impact assessment, health often isn't taken into account in the evaluation of environmental impact study [5]. The issues and definitions related to human health are still neglected, even if it is clear that enterprises from renewable and non-renewable sources are inducers of externalities with the increase of costs of services in the health system and with cultural and social changes in the territories in which they settle, representing a wide range of health risks $[3,7,8]$.

Results of a survey carried out by the Ministry of Health in 2008 demonstrated the participation of the health sector in the environmental licensing processes in force at the federal level, during the period from 2004 to 2007 . The survey identified 22 projects of different typologies, of which were analyzed 36 environmental studies by the health sector [7]. Of the total of studies analyzed by the health sector, only $50 \%$ had some type of recommendation incorporated as conditions in the environmental licenses issued by the federal environmental agency $[7,8]$. The reasons and limitations related to this result were identified as i) a lack of criteria defined by the licensing body to request the technical positioning of the health sector; ii) the health sector is not always considered as essential to the environmental licensing process; iii) the consultation of more than one organism can mean an obstacle to the licensing process, among others [7]. In addition, it was found that some public sectors responsible energy undertaking in Brazil do not consider the health subject as essential to the environmental licensing process, only when the project is in endemic areas of malaria motivated by mandatory compliance of the Brazilian Ministry of Health [7-9]. 
There is, in fact, a more complete understanding of how environmental factors interact with social and health determinants and a greater awareness of the relationship between health and the environment, yet the health issue is not being treated in an integrated way to the issues related to health environment and economic growth, hampering the achievement of sustainability to new and more ambitious global environmental policies [7].

Health workers that focus on health needs and do not understand the relationships between the health and the environment, often neglect the potential to improve health through better ecosystem services and reduction of environmental risk factors $[1,2,10]$. Thus, it is of paramount importance the involvement of several sectors on the formulation of sustainable public policies that consider health as an essential factor in the search for the construction of environmentally and socially balanced territories $[1,2,11]$.

\section{Methodology}

The present work was born from the curiosity to understand how the health issue is treated in environmental licensing of a large HPP, recently implemented in the Amazon region, and the role developed by the Brazilian Ministry of Health in the definition and monitoring of strategies and actions in health to compose the environmental licensing of these enterprise, in order to guarantee quality health care. Considering the complexity of the theme, we opted for the single case study modality, through the study of the environmental licensing of the Jirau Hydro Power Plant (HPP), on the health theme.

\subsection{Selection of the Study Area}

The choice of Jirau HPP was due to its location in the Amazon, more specifically $100 \mathrm{~km}$ from the capital of the state of Rondonia, Porto Velho, a region that has ecological, economic and cultural characteristics that make it more susceptible to impacts, due to high endemicity diseases, traditional populations with limited adaptive capacity, and a poor health care system [12, 4]. This project shares the health impacts common to large-scale ventures in remote areas of Brazil [4].
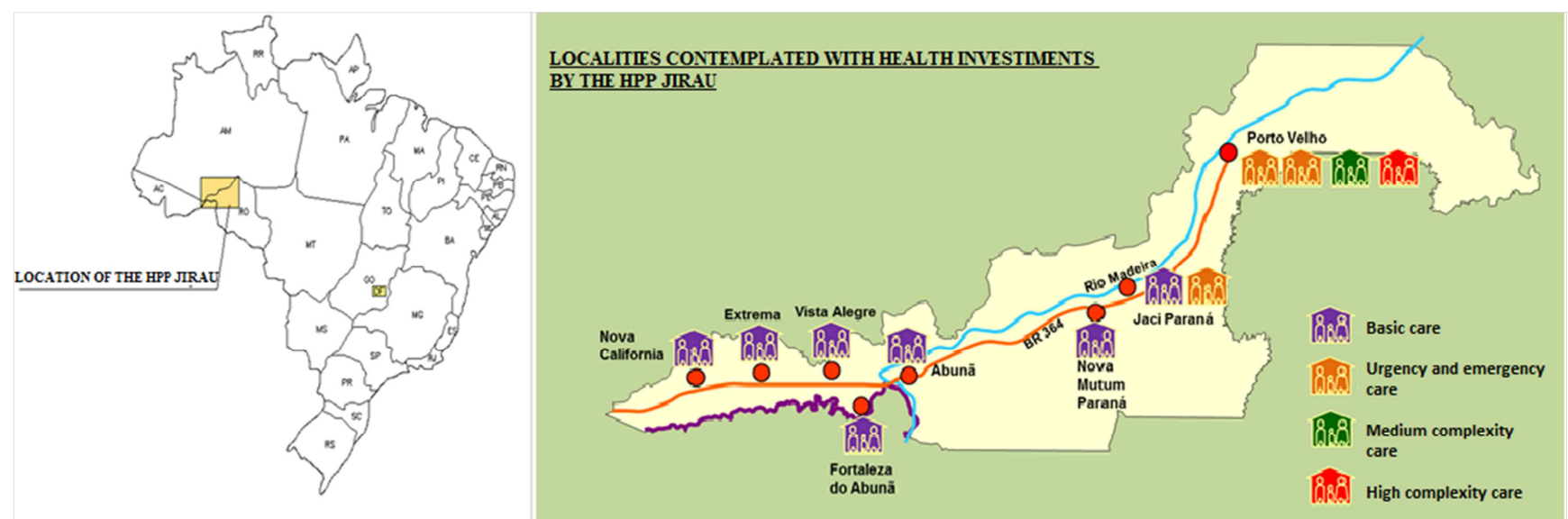

Figure 1. Map Indicating the location of the HPP Jirau (Data Source: 14, 20).

The localities directly interfered by the HPP Jirau are characterized by a low quantitative of population: Mutum Paraná, Jaci Paraná Abunã and Fortaleza do Abunã. In these areas, there are sites and farms whose owners reside in the urban center of Porto Velho or other municipalities, leaving their properties to the care of rural caretakers [13, 14]. According to the demographic census carried out by the Brazilian Institute of Geography and Statistics, in 2000, the urban center of Jaci Paraná had a population of more than 1,500 inhabitants, while in other districts this number was below 500 inhabitants [15].

Except for public structures, the constructive pattern of the region consists of wooden houses, depending on the availability of this natural resource in the region. In 2008, only $9 \%$ of the private households in the city of Porto Velho were connected to the general sewage network, presenting precarious sanitary sewage conditions, as well as water abstraction through rudimentary and septic tanks. In some cases, sewage was dumped outdoors in the woods and streams $[13,14]$.
Most of the localities did not have electricity supply in 2010, even though the Federal Government program "Luz para Todos" and Transmission Lines already existed. Except for the locations of Embaúba, Jirau and Ramal 31 de Março, which had electric grid, the other localities had individual light generation, made by means of fuel generators, lamps, candles and, in rare cases, solar energy panels. The region did not have television antennas nor mobile telephony, although internet was available at Jaci Paraná, and to find these services one had to travel long distances $[13,14]$.

In 2010 and still now the garbage cleaning was monthly made by the Municipality in some localities through the transportation to the nearest "landfills". Even though it is still common to find in the junk spread in the bush, river bank and routes. Some residents opt for the burning or burial of waste $[13,14]$.

The few existing health units provide health care education; treatment and diagnosis of malaria; medical and nursing consultations with laboratory support and dental care, ambulatory and observation health care. 


\subsection{Survey Method}

The first step to attain objectives of the present study consisted on reviewing the existing literature on the occupation of the State of Rondônia and the implementation of the HPP Jirau, in order to understand the relation between the geographic space, the resident population, the main political, economic and social characteristic, the local culture, and the public health care system.

\subsection{Study Indicators}

According to the 2010 Census, 53\% and 94\% of the populations of the Jaci Paraná and Mutum Paraná Districts reside in the rural area of the municipality of Porto Velho [17], often dispersed in vast areas, making it difficult to guarantee universal access to basic health services through of the traditional method of health centers $[13,14]$. This reality requires the adoption of indicators and strategies aimed to basic health care, centered on the strategies to improve families' health, through visits to residence of vulnerable populations $[1,4]$.

The indicators chosen for health monitoring were divided into three main groups: i) indicators to measure the installed capacity of the health centers; ii) indicators to me measure the coverage of the public health care system; iii) outcome indicators of basic health care.

The quantitative indicators to measure the capacity of the health centers resulted from data collected from 2008 to 2014 at the health centers of the districts of Jaci Paraná, Mutum Paraná, Nova Mutum Paraná, Abunã and Fortaleza do Abunã, directly interfered by the Jirau HPP, and where calculated according to the parameters of the Brazilian Administrative Rule n. 1.101/GM of June 12, 2002 [16].

The qualitative indicators to measure the coverage of the public health care system and the outcome of basic health care were based on the results of questionnaires applied to 181 families directly affected by the Jirau HPP ( $84 \%$ of the resettled and indemnified population by the HPP Jirau). The methodology consisted on the application of structured questionnaires, in different time slots, prior to the resettlement or indemnification of the population (2010), to the stabilization of the interviewee in the new place or in the remainder of their property (2012). Four stages of monitoring were carried out in 2010, 2011, 2013 and 2014 [17, 18].

\subsection{Data Analysis}

The data was computed, organized and processed to compose the qualitative-quantitative indicators proposed by the author in the present work. Once the indicators were structured, an integrated analysis of the results was carried out to identify the changes in health before and after the implementation of the HPP and highlighting the alterations for specific health topics.

\section{Results}

\subsection{Installed Capacity of the Health Units}

Observation beds, also called short-term hospitalizations, are commonly located in emergencies, outpatient clinics or day hospitals and are used for up to 24 hours of care for nursing procedures, specialty consultation and complementary examinations [19].

In the individual districts analysis, from 2008 to 2009, the districts of Abunã and Fortaleza do Abunã had 1.2 and 2.3 observation beds available per thousand inhabitants at the health units, respectively. Jaci Paraná and Mutum Paraná had each 0.1 and 0.2 observation beds per thousand inhabitants in the same period, respectively. As of 2011, the availability of beds per thousand inhabitants at the health unit of Fortaleza do Abunã practically doubled: the population remained stable and there was an additional bed. Jaci Paraná presented the largest increase in bed availability, from 0.1 observation beds per thousand inhabitants in 2008, 0.7 in 2011 and 1 bed per thousand inhabitants in 2014 (Figure 2).

In the overall analysis of districts from 2008 to 2010 there were 0.2 observation beds per thousand inhabitants ( +4 beds), from 2011 to 2013, 0.6 beds per thousand inhabitants ( +13 beds) and, since 2014, 0.8 beds for each thousand inhabitants $(+18$ beds), totaling an increase of 14 observation beds (Figure 2).

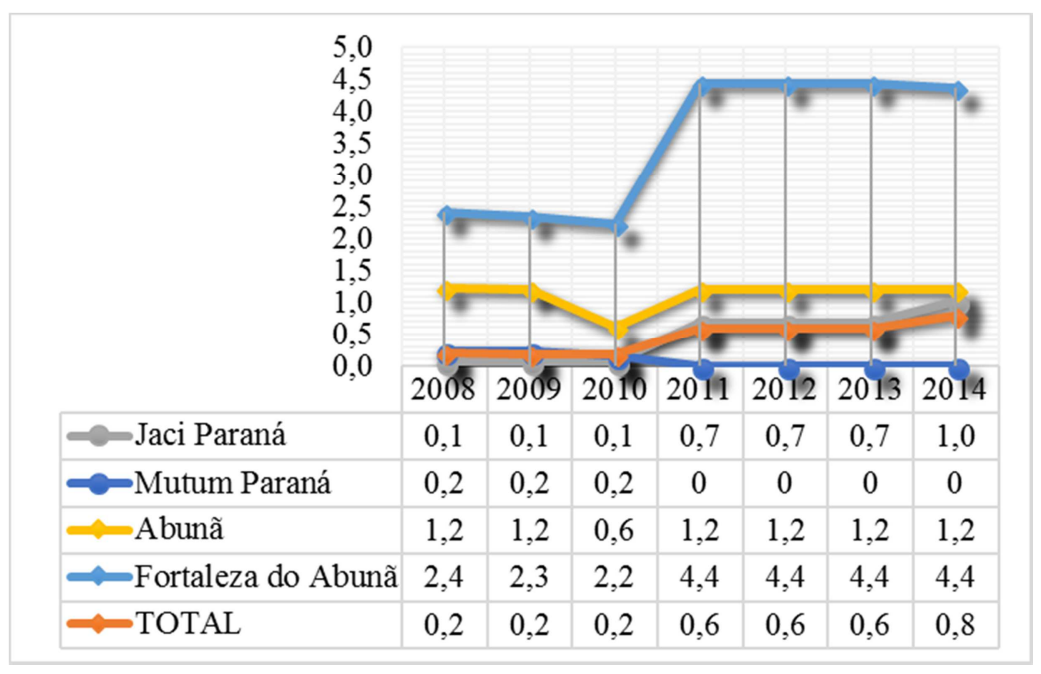

Figure 2. Installed capacity of health units to house observations beds. 
In 2008 Jaci Paraná, the largest of the three target localities of this study, had an average installed capacity of 0.8 consultations per inhabitant/year, insufficient to meet the local population according to Brazilian Ministry of Health: 2 to 3 consultations per inhabitant/year [16]. Since 2011, with the construction of the health unit of Nova Mutum Paraná and the renovation of health unit of Jaci Paraná, the number of doctors' offices available in Jaci Paraná has evolved from 1 to 6 and the scenario in this locality was reversed. From then on, the installed capacity of the health unit in this locality was superior to the one recommended by the Brazilian Ministry of Health [16]. As for the health units of Abunã and of Fortaleza do Abunã, since 2008 the installed capacity of medical consultations per inhabitant/year was above the minimum recommended Brazilian Ministry of Health (Figure 3) [16].

In a global analysis, the health unit of the studied locations have an average installed capacity of 2.3 consultations per inhabitant between 2008 and 2010 and of 3.3 between 2010 and 2014, above the recommended by the Brazilian Ministry of Health (Figure 3) [16].

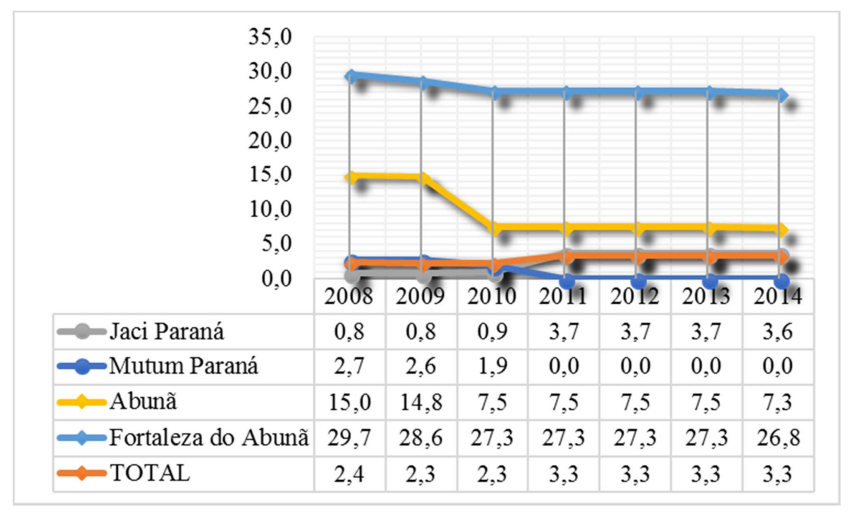

Figure 3. Installed capacity of medical consultations per health unit.

The improvements made by the entrepreneur increased the installed capacity of the health units of Abunã, Fortaleza do Abunã and Jaci Paraná, allowing the expansion of the health assistance beyond these districts. The construction a new health unit, located at Nova Mutum Paraná, in substitution for the deactivation of heath unit at Mutum Paraná, also increased the installed capacity of healthcare in the region by more than $50 \%$. Since 2011, the installed capacity has doubled in the units of Abunã and Fortaleza do Abunã and quintupled in the units of Jaci Paraná, of which Nova Mutum Paraná is part $[13,14,18]$.

\subsection{Health Care}

The construction of the health unit of Nova Mutum Paraná (2011) and improvements made in the health unit of Jaci Paraná, reversed the health care scenario in the studied districts. The installed capacity of the health units proved to be sufficient to meet the local population and the minimum requirements by the Brazilian Ministry of Health [16]. But, although there was sufficient infrastructure and equipment to meet the local population since 2011, doubts remain about the efficiency of the municipal management, its ability to coordinate the performance of the available human resources and adopt management strategies appropriate to the basic needs of the population $[17,18]$.

From 2008 to 2010 the human resources mobilized were sufficient to serve the local population. After 2010 this framework drastically changed due to a reduction in human resources and, consequently, demobilization of the personnel. In Jaci Paraná, the health unit had personnel to cover only $20 \%$ of the local population (Figure 4 ).

Overall, although the number of mobilized teams doubled in the studied districts, it remained substantially lower than the installed capacity of the health units of up to 5 teams, and thus was insufficient to meet the local population. In 2014, the health personnel mobilized served approximately half of the local population of Jaci Paraná, Abunã and Fortaleza do Abunã (53\%), bellow the recommended by the Brazilian Ministry of Health (Figure 4) [16].

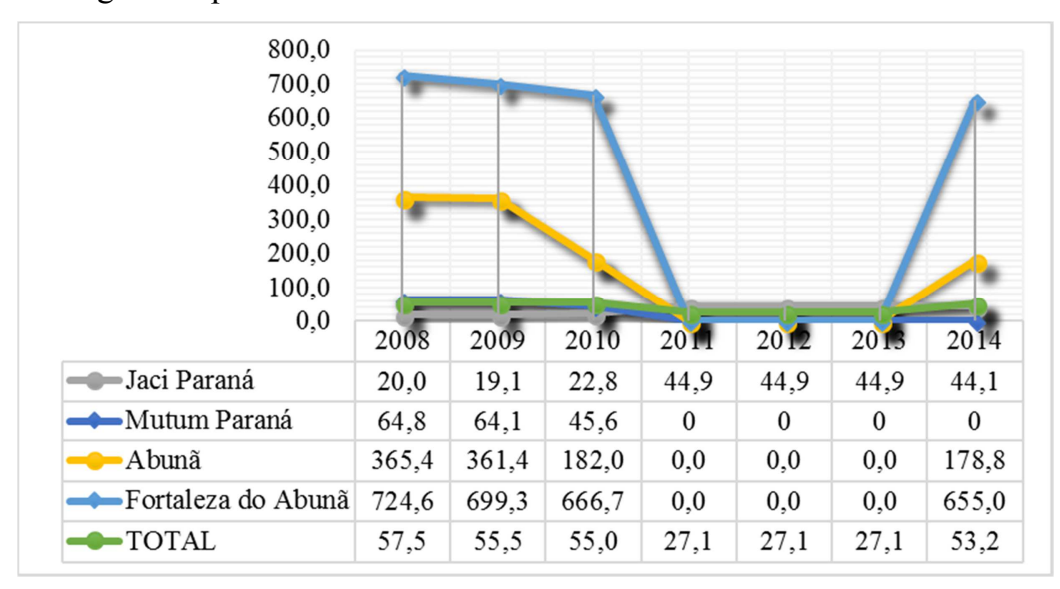

Figure 4. Coverage of health teams per thousand inhabitants.

The results of the qualitative indicators indicated that $47 \%$ of the population interviewed judged the quality of care in the health units to be good, $37 \%$ thought it was regular and $15 \%$ thought it was bad. In 2014, 28\% judged good, 45\% regular, $24 \%$ bad and $3 \%$ did not report (Figure 5). Some of the interviewees also reported that the unit of health of Nova 
Mutum Paraná lacked staff and resources for health care and that in 2012 the unit did was not open during the evenings and that there were no doctors available on weekends. Another controversial point was the lack of an ambulance in the unit, donated by the entrepreneur through the Municipality of Porto Velho, and the presence of a physician coming from the Federal Government Program called Mais Médicos [19].

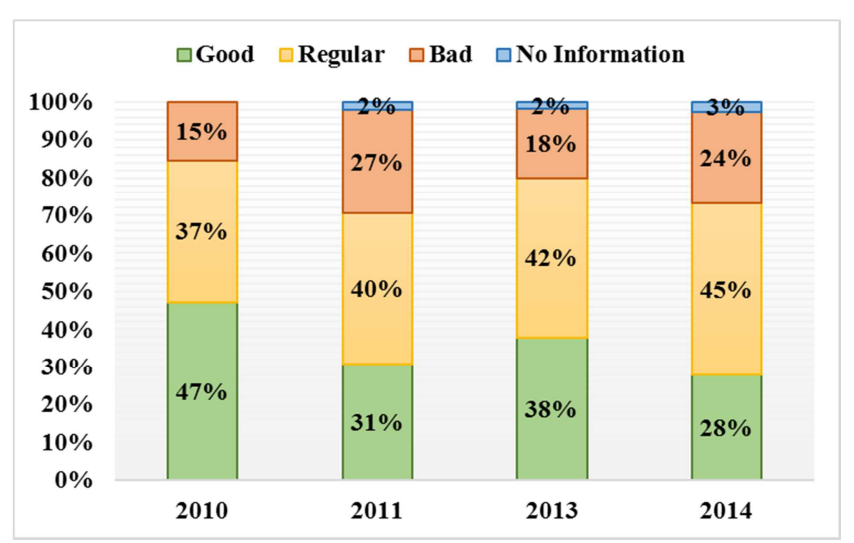

Figure 5. Quality of the health care provided in the health units according to the interviewed population.

The community agent is responsible for the link between the community and health services, through the monitoring and guidance of health service users, supporting health promotion and protection, and in the identification of possible health risks, by notifying the occurrence of diseases requiring vigilance [4]. The service provided by the community agent has great importance in the prophylactic monitoring of families, as well as it is essential for scheduling consultation of families at the public health units. Since 2008 these professionals have been satisfactory in quantity to the districts of Jaci Paraná, Abunã and Fortaleza do Abunã, even if it is close to the limit recommended by the Ministry of Health [16]. On the other hand, the results of the qualitative indicators indicated an aggravation in the dissatisfaction of the local population about the care of these agents: in $2010,82 \%$ of the interviewees claimed that the that community agents were available, against $18 \%$ who claimed they did not exist. In 2014, this percentage rose to $36 \%$ and $64 \%$, respectively (Figure 6).

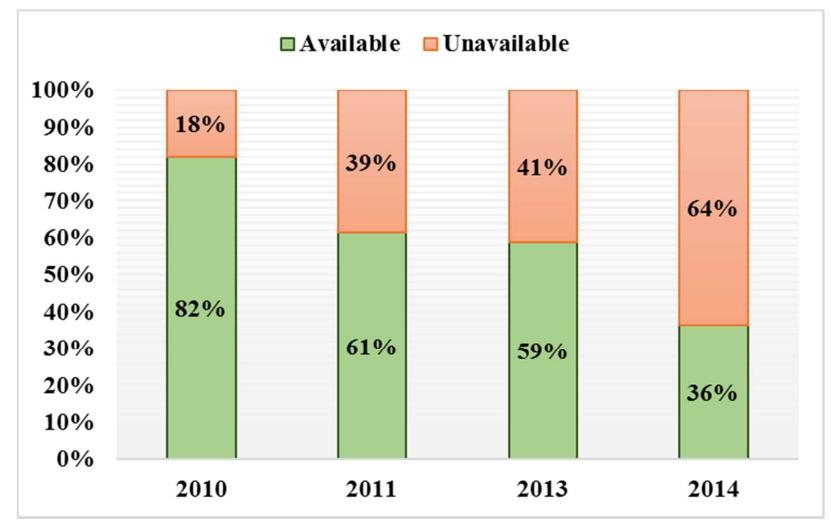

Figure 6. Medical availability in the heath units according to the interviewed population.
When questioned about the frequency of visits by community agents, in 2010, 51\% of those interviewed claimed to be biweekly, $17 \%$ monthly and $32 \%$ undetermined. In 2014, 3\% claimed to be biweekly, $9 \%$ monthly and $89 \%$ undetermined (Figure 7).

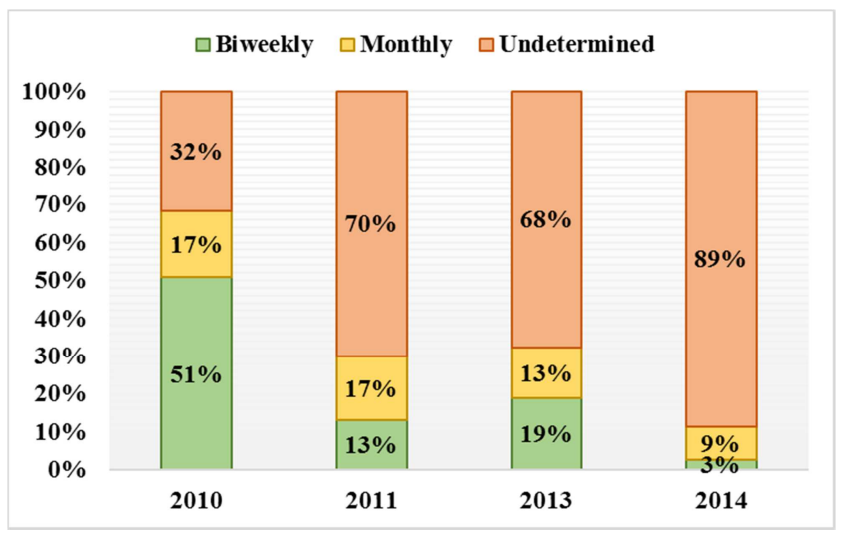

Figure 7. Frequency of the health care provided by the community agent according to the interviewed population.

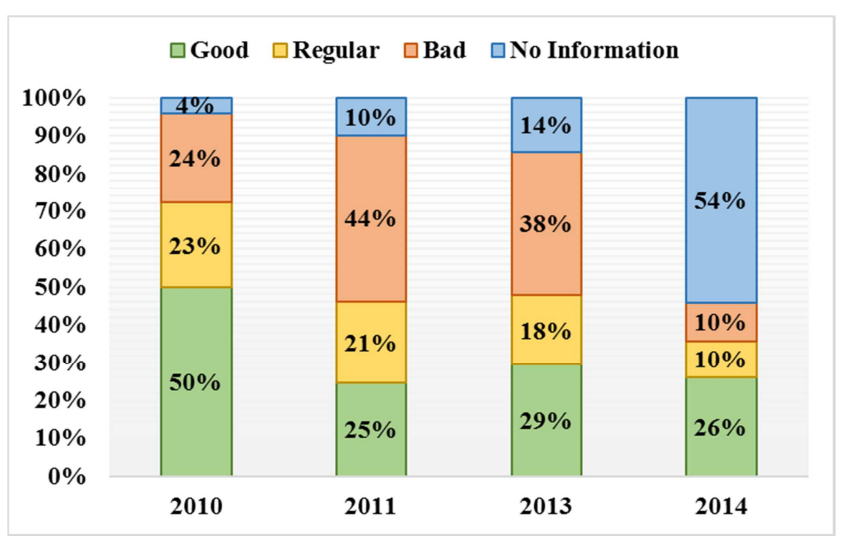

Figure 8. Quality of the health care provided by the community agent according to the interviewed population.

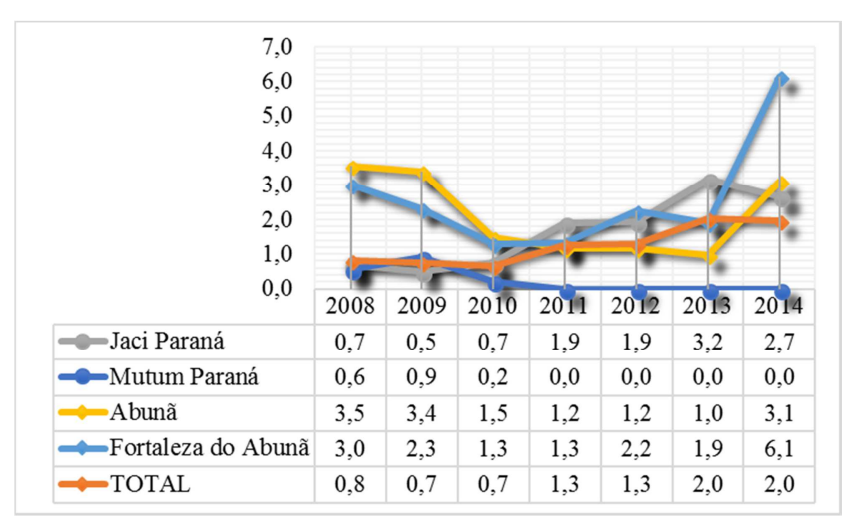

Figure 9. Number of public medical consultations registered per health unit.

Also, in $2010,50 \%$ of the interviewed population judged the attendance of the agents as "good", 23\% as "regular", 24\% as "bad" and the remaining 4\% did not respond (no information). In 2014 , this percentage increased to $26 \%, 10 \%, 10 \%$ and $54 \%$, respectively (Figure 8 ). Of those who did not respond in the interviews (without information), part is not attended by 
community agents. In an informal conversation, the interviewees reported that the number of staff available by the Municipality of Porto Velho for the role of community agents decreased significantly after 2008, making it impossible for all families to be attended. Others said that the agents only serve the district headquarters and not the rural areas.

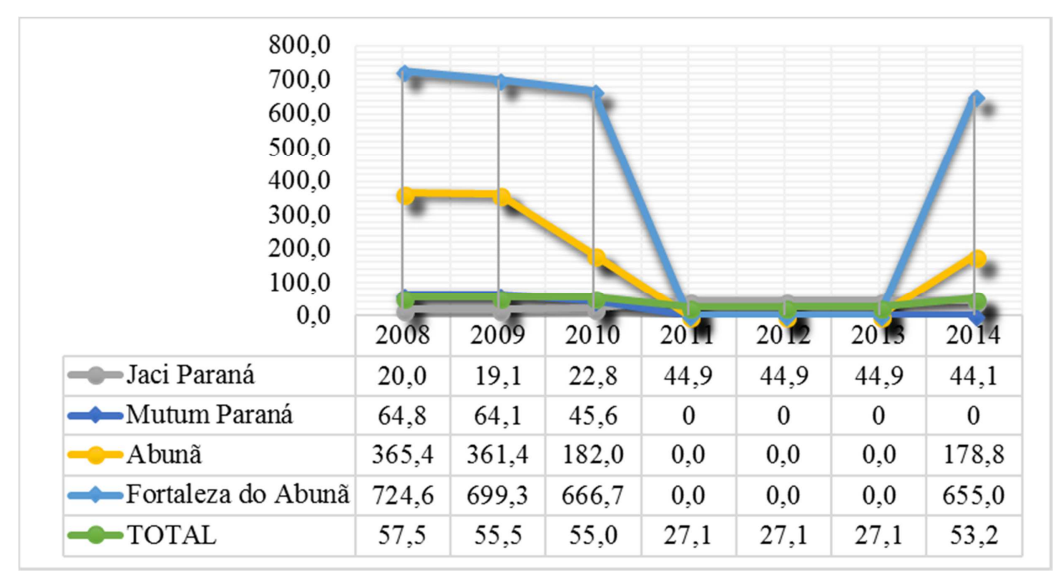

Figure 10. Coverage of active medical teams per thousand inhabitants in each studied location.

\subsection{Access to Health Units}

The results of the qualitative research indicated that in 2014 the health units were closer to users' dwelling places, especially for residents of Nova Mutum Paraná, Jaci Paraná and Abunã. Despite this proximity, the frequency of use of UBS by the population directly affected by the HPP Jirau reduced between 2014 and 2010, being restricted, in most cases, to periodic attendance and emergencies. In 2010, the frequency of use of the health unit by the interviewees was frequent for $27 \%$, sometimes for $65 \%$ and never for $8 \%$, compared to $11 \%, 85 \%$ and $4 \%$ in 2014, respectively (Figure 11).

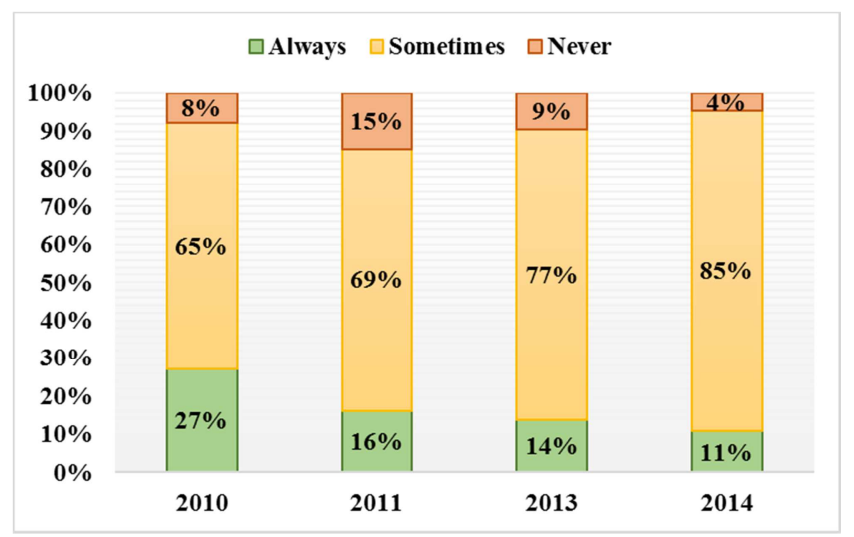

Figure 11. Frequency of attendance at health facilities according to the interviewed population.

\section{Discussion}

Overall, the installed capacity of all health units located in the Jirau's HPP Influenced Area were insufficient within the obligations of the Ministry of Health until 2010. The health conditions identified in the region affected by the implementation of the HPP Jirau lacked infrastructure, educational and medical assistance. The region was framed with a high rate of malaria contamination and characterized by an insufficient public health system to meet the local demand, present at all levels of assistance, from physical structure to insufficiency of human resources $[13,14]$.

Due to the minimum infrastructure found in the districts, they had a wide area of coverage of rural areas, branches and populations located on the banks of the Madeira River. Since 2011, the constructions and reforms carried out in the units of health by the plant's concessionaire have resulted in an increase of more than $50 \%$ in capacity to meet the population of these districts. Under the actual conditions (until 2014), the guidelines recommended by Brazilian Ministry of Health for basic health care are being met by studied health units from the point of view of the existing infrastructure [16].

However, despite significant improvements, the public mobilization of human resources mobilized was considerably lower than the installed capacity of these units and, therefore, insufficient to meet the local population. In 2014, the human resources available at the studied area served approximately half of the population (53\%) and were insufficient to attend the local population. As a consequence, the attendance of other units nearby were overstretched, due to the migration of the population in search of medical attention and the entrepreneur had to make occasional and emergency contributions in order to provide human resources to meet the demands of the local population, under the regime of temporary contracting, but perhaps not long enough to be perceived by the population and therefore reflected in the qualitative interviews applied.

In all localities, the number of physicians per thousand inhabitants is lower than that of nurses, the opposite of what occurs in the national average: basic indicators for health in Brazil indicate that the number of doctors per thousand inhabitants is almost three times higher of nurses, in the national average, between 1990 and 2005 [21]. In the studied localities, the average number of physicians mobilized in 07 years is 0.2 for a thousand inhabitants, compared to 0.4 nurses mobilized for a thousand inhabitants. Dentists mobilized between 2008 and 2014 were insufficient to meet the local population. In this matter, it was perceived that the 
human resources hired by the local government had a significant turnover of public employees, especially due to the different wage structures, geographic distances and the lack of standardization of contracts offered by the different municipalities [7, 22]. There were important failures in the public management of the human resources allocated in the health units located at Mutum Paraná, Jaci Paraná, Fortaleza do Abunã and Abunã until 2014 and related to the i) superspecialization and geographical distribution of personnel, ii) gap between training policies and health policy, iii) profile definition of personnel right after the graduation; iv) reorganization of primary care services. The personnel turnover and the quality of the medical care undertakes the relation with the patient and contributes to the precariousness of the health care [24]. Dissatisfaction about a health service can negatively influence the evaluation of the care of another service as shown in this study [25]: families not served by community agents tend to misjudge the service provided in the health units, since there is an increase in the waiting time for consultations in these units.

In general, there were improvements in the health conditions of this population, the most notable being the drop in Malaria and Dengue contamination in the region: in 2010, $96 \%$ of the respondents claimed to have had some tropical disease against 4\% in 2014 [8]. They also perceived greater health and hygiene care resulting from environmental education campaigns and improvements in the use of domestic sewage in homes [8]. In 2014, almost all respondents to qualitative research rely on basic sanitation, through septic tanks or public sanitation, as well as treated water. In addition, the oil generators were replaced by public energy supply, positively impacting the quality on the life of the families, who started to make use of household appliances. These perceived improvements directly influenced the health of the population directly affected by the HPP Jirau which became healthier and therefore less dependent on the health system. This result reinforces the thesis that the confrontation of problems of collective dimension should be done thought the promotion of health and disease prevention through education.

The obligations in health in the studied area were defined by the Ministry of Health (MS), local health secretariats and the entrepreneur. They were executed in compliance with the environmental HPP Jirau's licensing process and successful in assessing the existing public health deficiencies through investments to improve health infrastructures in regions directly interfered by the HPP Jirau. However, the entities involved in planning the health activity failed to anticipate investments needed to supply and train human resources to attend the health units, to avoid greater administrative burden of the local health secretariat, since the expansion of health units require, necessarily, hiring of human resources in greater number.

Public health indicators are an important quality measures since they can provide clues to the success or difficulties of local health services, meeting the expectations and needs of users. They are an important tool for research, planning and administration of health services and, despite the expansion of production and access to Brazilian health data, its organization still needs to be improved to contribute to local public policies in a more efficient way. The data produced in small health center is not made available in an accessible and transparent way to the population, who need to visit or phone the public health's units and departments to obtain them. There are still difficulties to register and publicize the results of health care within the health units, such as registration.

\section{Conclusion}

In this study we found out that the secretariat of health of Porto Velho has many great challenges: invest in education in health in order to understand the main causes of health problems of a certain region and to raise public awareness about the existing health problems, forms and mechanisms to prevent the contamination of certain diseases; invest in training of personal in order to produce and organize the health indicators so they can reflect the reality in the municipality and districts mentioned above; hire enough medical personnel to attend the studied locations and improve the management at all level.

This study also leads us to reflect on the need for health to go beyond technical and organizational aspects. They indicated the changes needed in the process of training and qualification of local health professionals and in the need to reinforce health education for patients, in which community agents play a fundamental role and, to that end, must be properly trained and oriented to deal with the most diverse publics. The results corroborate the need for humanization of health, especially in basic care, which is the gateway to public health services by the population.

\section{References}

[1] World Health Organization (WHO). Decreasing differences: the practice of policies on social determinants of health: a discussion paper. World Conference on Social Determinants of Health. Rio de Janeiro, 2011.

[2] Brazil. Ministry of Health. Secretariat of Health Surveillance; Department of Surveillance in Environmental Health and Worker's Health. Health Impact Assessment - AIS: methodology adapted for application in Brazil. Brasília: Ministry of Health, 2014. 68 p. il.

[3] Silveira M. The implantation of hydroelectric plants in the Brazilian Amazon, socioenvironmental and health impacts with the transformations in the territory: the Belo Monte HPP. Brasília: University of Brasília; 2016.

[4] Finkelman, J. Pathways of Health in Brazil. Rio de Janeiro: FIOCRUZ, 2002.

[5] Brazil. Presidency of the Republic. Law No. 6.938/1981, of August 31, 1981. Provides on the National Policy of the Environment, its purposes and mechanisms of formulation and application, and other measures; Official Journal of the Union 1981; 02 sep. 
[6] Brazil. National Council for the Environment (CONAMA). Resolution $\mathrm{n}^{\circ} 237$ of December 19, 1997. Regulates the aspects of environmental licensing established in the National Environmental Policy; Official Journal of the Union 1997; 22 dec.

[7] Silveira, M. The contribution of the health sector to environmental licensing processes: first approximations. Brasília: University of Brasília; 2008.

[8] Silveira, M. Interface between health and environment: aspects of health in the Environmental Impact Assessment of enterprises. In: Annals of the 5th National Meeting of Anppas; Florianópolis, 2010 Oct 4-7.

[9] Brazil. Ministry of Health (MS). Secretariat of Health Surveillance. Ordinance No. 47 of December 29, 2006. Provides on Malaria Potential Assessment and Health Status Certificate for agrarian reform settlement projects and for other enterprises in malaria endemic regions. Official Journal of the Union 2007; 30 dec.

[10] Breilh J. Pillages, Ecosystems and Health. In: Miranda AC, Barcellos C, Moreira JC, Monken M, organizers. Territory, environment and health. Rio de Janeiro: Fiocruz Publishing House; 2008. p. 159-177.

[11] Silveira M, Padilha JD, Schneider M, Amaral PST, Carmo TFM, Netto GF, Rohlfs DB. Perspective of health impact assessment in development projects in Brazil: strategic importance for sustainability. Cad Saude Coletiva 2012; 20 (1): 57-63.

[12] Brazil. United Nations Program; João Pinheiro Fundation and Institute of Applied Economic Research. Atlas of Human Development, Rondônia, 2017.

[13] Abaeté; Sustainable Energy from Brazil. Qualitative Complementary Study of Socioeconomic and Cultural Aspects of Localities in the AHE Influence Area Jirau, Rio de Janeiro, 2008.

[14] Cnec Worley Parsons; Sustainable Energy from Brazil. Socioeconomic Monitoring Report, Area of Direct Influence of the Jirau Hydroelectric Plant and Municipality of Porto Velho, Part I and Part II, May 2013.

[15] Brazil. Brazilian Institute of Geography and Statistics (IBGE). Directorate of Research, Coordination of Population and Social Indicators, Research Studies, Demographic and
Socioeconomic Information n. 25, Sociodemographic and Health Indicators in Brazil. Rio de Janeiro, 2009.

[16] Brazil. Ministry of Health (MS). Secretariat of Health Surveillance. Ordinance No. 1,101 of June 12, 2002. Establishes, among others, that the parameters of health care coverage be established by the National Directorate of the Unified Health System - SUS, approved by the National Health Council; Official Journal of the Union 2002; 13 jun.

[17] Oikos Consulting and Projects; Sustainable Energy from Brazil. Report on Monitoring of the Area of Direct Influence T6, n. 02/2016, 2016.

[18] Systemic Social Assistance (ASSIST), Sustainable Energy of Brazil. Monitoring of Social Reinsertion and Evaluation of the Quality of Life Recomposition of the Population Affected by the Jirau Hydroelectric Power Plant (UHE Jirau) - T0 to T3. Old Town, 2015.

[19] Brazil. Presidency of the Republic. Law no. 12.871 of October 22, 2013. Establishes the Program "Mais Médicos", amends Laws 8.745 of December 9, 1993, and 6.932 of July 7, 1981, and makes other provisions. Official Journal of the Union 2013; Oct 23.

[20] Brazil. Federal Council of Medicine (CFM). Resolution n. 2.077 / 14. Standardizes the operation of emergency and emergency hospital services, as well as the size of the medical staff and the work system; Official Journal of the Union 2014; Jul 24.

[21] Interagency Information Network for Health, Pan American Health Organization. Basic indicators for health in Brazil: concepts and applications / Interagency Network for Health Information - Ripsa. - 2. ed. - Brasília: Pan American Health Organization, 2008. 349 p. Il.

[22] Gil, C. R. R. Human resources training in family health: paradoxes and perspectives. Caderno Saúde Pública, Rio de Janeiro, 2005.

[23] Leme Engineering. EIA - Study of Environmental Impact Studies Rio Madeira - RO, May 2005.

[24] Girardi, J. B. Preliminary results: Family Health in Bahia. Belo Horizonte: NESCON / UFMG, 2008.

[25] Paim J. S. et al. The Brazilian health system: history, advances and challenges. The Lancet, London, v. 377, n. 9779, p. 1778$1797,2011$. 